\title{
Article
}

\section{Influential Path of Social Risk Factors toward Suicidal Behavior-Evidence from Chinese Sina Weibo Users 2013-2018}

\author{
Yujin Han ${ }^{1,2}$, He Li ${ }^{1,3}$, Yunyu Xiao ${ }^{4}$, Ang Li ${ }^{5}$ and Tingshao Zhu 1,3,*(D) \\ 1 Institute of Psychology, Chinese Academy of Sciences, Beijing 100101, China; hanyujinruc@163.com (Y.H.); \\ lih@psych.ac.cn (H.L.) \\ 2 Department of Statistics, Renmin University of China, Beijing 100872, China \\ 3 Department of Psychology, University of Chinese Academy of Sciences, Beijing 100049, China \\ 4 Silver School of Social Work, Indiana University-Purdue University Indianapolis, \\ Indianapolis, IN 46202, USA; yx18@iu.edu \\ 5 Department of Psychology, Beijing Forestry University, Beijing 100083, China; angli@bjfu.edu.cn \\ * Correspondence: tszhu@psych.ac.cn
}

Citation: Han, Y.; Li, H.; Xiao, Y.; Li, A.; Zhu, T. Influential Path of Social Risk Factors toward Suicidal Behavior-Evidence from Chinese Sina Weibo Users 2013-2018. Int. J. Environ. Res. Public Health 2021, 18 2604. https://doi.org/10.3390/ ijerph18052604

Academic Editor: Paul Tchounwou

Received: 7 January 2021

Accepted: 25 February 2021

Published: 5 March 2021

Publisher's Note: MDPI stays neutral with regard to jurisdictional claims in published maps and institutional affiliations.

Copyright: (c) 2021 by the authors. Licensee MDPI, Basel, Switzerland. This article is an open access article distributed under the terms and conditions of the Creative Commons Attribution (CC BY) license (https:// creativecommons.org/licenses/by/ $4.0 /)$

\begin{abstract}
Purpose: The purpose of this study was to determine suicidal risk factors, the relationship and the underlying mechanism between social variables and suicidal behavior. We hope to provide empirical support for the future suicide prevention of social media users at the social level. (2) Methods: The path analysis model with psychache as the mediate variable was constructed to analyze the relationship between suicidal behavior and selected social macro variables. The data for our research was taken from the Chinese Suicide Dictionary, Moral Foundation Dictionary, Cultural Value Dictionary and National Bureau of Statistics. (3) Results: The path analysis model was an adequate representation of the data. With the mediator psychache, higher authority vice, individualism, and disposable income of residents significantly predicted less suicidal behavior. Purity vice, collectivism, and proportion of the primary industry had positive significant effect on suicidal behavior via the mediator psychache. The coefficients of harm vice, fairness vice, ingroup vice, public transport and car for every 10,000 people, urban population density, gross domestic product (GDP), urban registered unemployment rate, and crude divorce rate were not significant. Furthermore, we applied the model to three major economic development belts in China. The model's result meant different economic zones had no influence on the model designed in our study. (4) Conclusions: Our evidence informs population-based suicide prevention policymakers that incorporating some social factors like authority vice, individualism, etc. can help prevent suicidal ideation in China.
\end{abstract}

Keywords: suicidal behavior; social media; path analysis model

\section{Introduction}

Suicide is a serious global public health problem. Nearly 800,000 people commit suicide every year, and more people have suicidal thoughts [1]. In China, about 100,000 people die from suicide every year [2]. Therefore, it is necessary to identify important risk factors and mechanisms that link suicidal behaviors in order to design effective suicide prevention programs.

Suicidal behavior is considered to result from a complex interaction among biological, psychological, and social variables [3,4]. Many researchers have designed studies to discuss the influence of social factors on suicidal behavior, but there have been deficiencies. (1) The first is a lack of data. Relevant research has mostly relied on case studies, regional comparisons, field investigations, individual cases, and other qualitative methods to summarize the impact of social variables on suicidal behavior [5,6]. However, the sizes of the samples from these studies have been relatively small, so the conclusions may not be generalizable. (2) They have mainly been cross-sectional studies [7-9]. This means it has been difficult to make causal inferences. (3) Few psychological factors have been considered 
as mediating mechanisms. Some scholars have analyzed the relationship between suicide rates and social variables based on a large amount of data using time series models [10], but such studies have often focused on quantitative relationships while ignoring psychological factors and the influence of social factors on suicide. The stress-susceptibility model has shown that it is necessary to consider the psychological factors of suicide [11,12].

To solve the shortcoming of the lack of data, this study used large social media data and official statistics to examine the quantitative relationships between social variables and suicidal behavior. The data were obtained from the National Bureau of Statistics and Sina Weibo (a Chinese version of Twitter) in 2013-2018. Compared with the traditional methods, Sina Weibo can provide us with a large amount of data and a new research perspective. Sina Weibo is the largest microblog platform in China. Users can post text, pictures, or videos to share their lives and opinions in real time. Related studies have pointed out that some people tend to choose social media to express their abnormal emotions [13]. Thus, the social media platform is convenient for the study of suicidal behavior. Recently, social media such as Sina Weibo have acted as a common platform to conduct suicide research. In 2017, Liu et al. [14] proposed to actively identify potential suicides based on social media. Tian et al. [15] used deep learning models to predict suicide on Weibo in 2018. These studies prove the feasibility and rationality of suicide research through Sina Weibo.

In the meantime, we used the path analysis model and introduced the mediator, psychache, into our model. We hypothesized that the underlying mechanism of suicidal behavior and social factors was that social factors induced negative emotions (e.g., psychache), and negative emotions led to suicidal behavior. A negative emotion like psychache was the mediating factor; social factors cannot directly lead to suicidal behavior. We made the hypothesis based on the "stress susceptibility" model [11]. Suicide is supposed to be the result of the interaction between stress variables and individual quality. "Stress" refers to a state of tension caused by changes in dangerous or unexpected external conditions. When an individual encounters stressing events, this may lead to disorders and negative emotions. In addition, social variables can only be regarded as negative life events that are a kind of "stress source" for suicidal behavior [16,17], rather than negative emotions. "Stress sources" cannot directly led to suicidal behavior. Thus, we speculated that social factors need to lead the emergence of disorders and negative emotions, and then make individuals commit suicide. We chose psychache as the representative of negative emotions. This is because according to Shneidman's theory [12], as a negative emotion, psychache (negative hurt, mental pain, soreness) is the cause of all suicidal behaviors, and other psychological variables (such as depression) are only related to psychache [12]. Shneidman's theory has been confirmed by a large number of studies $[18,19]$. We can show the above analysis in Figure 1.

\begin{tabular}{|c|c|c|}
\hline $\begin{array}{c}\text { social factors } \\
\text { (stressing events) }\end{array}$ & $\longrightarrow \begin{array}{c}\text { Psychache } \\
\text { (disorders and negative emotions) }\end{array}$ & $\longrightarrow$ suicidal behavior \\
\hline
\end{tabular}

Figure 1. Path analysis model designed.

\section{Method}

\subsection{Participants and Data Collection}

First, we collected Weibo posts to calculate their suicidal behavior and mediator, psychache, as measured by suicidal behavior and psychache in the Chinese Suicide Dictionary. We downloaded and extracted all public micro blogs of Chinese mainland users during 2013 to 2018 through the application programming interface (API). Then, from the data pool, we selected Sina Weibo users living up to the following criteria: (1) Registered before January 2013 (2) Authentication type was non-institutional and non-business. (3) Had posted at least one original Weibo per month from 2013 to 2018. The final data included 4 billion micro blogs, involving 1,160,000 Sina Weibo users and 31 provincial administrative regions of Chinese mainland (excluding Hong Kong, Macao, and Taiwan). After that, 
we employed the "TextMind" system developed by the Computational CyberPsychology Laboratory at the Institute of Psychology, Chinese Academy of Sciences, to process the word segmentation of Weibo posts and calculate word frequency of target words in each provincial administrative region every year. Ethical approval of the research was obtained and the ethics code is H15009, approved by the Research Ethics Committee of the Institute of Psychology, Chinese Academy of Sciences. In addition, we described the Chinese Suicide Dictionary in Section 2.1.1.

Then, we artificially divided social factors that have been confirmed to be related to suicidal behavior into three categories. These indicators focus on different aspects of social factors. They include cultural/value factors, economic factors, and other factors.

For cultural/value factors, we collected variables identified as suicide risks in the previous literature, including individualism and collectivism [20], social morality [21]. We calculated the word frequencies of cultural/value factors based on Cultural Value Dictionary and Moral Foundation Dictionary. We described the Cultural Value Dictionary and Moral Foundation Dictionary in Sections 2.1.2 and 2.1.3. We found the target words from dictionaries mentioned above, and calculated the defective words reflecting collectivism, individualism, and social morality in a similar way to calculating the frequency of suicidal behavior and psychache.

For economic factors, we collected variables identified as suicide risks in the previous literature. They were gross domestic product (GDP) and disposable income of residents [22]. Data of disposable income of residents and GDP from National Bureau of Statistics were used in the study.

For other factors, we collected variables identified as suicide risks in the previous literature, including urbanization [23-25], unemployment [26], marriage [27]. More specifically, three indicators were selected to quantify urbanization. First, according to the definition of urbanization, the analysis chose the ratio of the growth value of the primary industry to the regional GDP as an indicator to measure the proportion of the primary industry in urbanization. Second, according to the research of Wang et al., the urban population density, and public transport and car for every 10,000 people were taken as the index of population urbanization and social urbanization [28]. All data were from National Bureau of Statistics.

\subsubsection{Chinese Suicide Dictionary}

The words reflecting suicidal behavior and psychache were selected from Chinese Suicide Dictionary. Meizhen LV et al. [29] published the Chinese Suicide Dictionary in 2015, which contained 13 dimensions of suicide expression, a total of 2168 words. The details of the dictionaries are shown in Table 1.

Table 1. Chinese suicide dictionary.

\begin{tabular}{|c|c|c|c|}
\hline Category & Definition & Number of Words & Representative Words \\
\hline Suicide ideation & Words reflecting suicidal thoughts & 586 & want to die escape \\
\hline Suicidal behavior & Words reflecting self-harm behaviors & 88 & seppuku hypnotics \\
\hline Psychache & Words reflecting psychological distress & 403 & want to cry loneliness \\
\hline Mental illness & Words reflecting poor mental health status & 48 & depression hallucination \\
\hline Hopeless & Words reflecting a feeling of despair & 188 & dead end despair \\
\hline Somatic complaints & Words reflecting somatic symptoms & 183 & headache shortness of breath \\
\hline Self-regulation & Words reflecting an attempt to push oneself hardly & 36 & repression force oneself to smile \\
\hline Personality & Words reflecting negative personality inferiority & 72 & complex hate oneself \\
\hline Stress & Words reflecting pressure in daily life & 83 & failure pressure \\
\hline Trauma/hurt & Words reflecting traumatic or unpleasant experiences & 182 & get dumped infidelity \\
\hline Talk about others & Words reflecting one's relatives and friends & 47 & partner son \\
\hline Shame/guilt & Words reflecting a feeling of shame and guilt & 72 & lose status making an apology \\
\hline Anger/hostility & Words reflecting a feeling of angry and hostile against others & 180 & damn it curse \\
\hline
\end{tabular}

\subsubsection{Cultural Value Dictionary}

The Cultural Value Dictionary is regarded as the quantification of individualism and collectivism. Based on the cross-cultural research of individualism and collectivism, and the help of expert group discussion, the Chinese words related to individualism and 
collectivism are finally determined [30]. There are 53 words of individualism, such as "I", "competition", and 64 words of collectivism, such as "we" and "dedication". The details of the dictionaries are shown in Table 2.

Table 2. Cultural value dictionary.

\begin{tabular}{cccc}
\hline Category & Definition & Number of Words & Representative Words \\
\hline Individualism & Words reflecting individualism & 53 & Independence autonomy \\
Collectivism & Words reflecting collectivism & 64 & Team cooperation \\
\hline
\end{tabular}

\subsubsection{Moral Foundation Dictionary}

The Moral Foundation Dictionary is a measure of social morality. Based on the basic theory of morality, the Chinese Revision of the dictionary of morality was carried out [31,32]. According to the two aspects of morality, that is, "Virtue" and "Vice", the amendment divides the five foundations of moral theory (care, fairness, loyalty, authority, holiness) into 10 dimensions, positive and negative. The specific "Virtue" includes purity virtue, authority virtue, ingroup virtue, fairness virtue and harm virtue. The corresponding "Vice" includes five dimensions: purity vice, authority vice, ingroup vice, fairness vice and harm vice. In order to avoid too many variables increased the complexity of our model, only negative dimensions of the dictionary (purity vice, authority vice, ingroup vice, fairness vice and harm vice) were used to analyze the impact of social morality on suicidal behavior. The details of the dictionaries are shown in Table 3.

\subsection{Data Analysis}

In our data analysis, the null value in the data was removed. We took the "year" and the "province (or autonomous region)" as the granularity and finally formed 6 (Time) and 31 (Cross-section), a total of 186 sets of data. Moreover, in order to adjust the dimensions of different variables, the original data was standardized on the basis of standard deviation by Z-score. Then, according to the "stress susceptibility" model [11] and Shneidman's theory [12], we designed the path analysis model with mediation psychache. This means that in our model, 14 social variables only affected suicidal behavior through psychache. In addition, for assessment of path analysis model fit, we used the root mean square error of approximation (RMSEA), the chi-square/DOF ratio ( $\left.\chi^{2} / \mathrm{df}\right)$, Bentler-Bonett normed fit index (NFI) and comparative fit index (CFI). Acceptably, a CFI and NFI greater than 0.90, a RMSEA less than 0.10 and $a$ chi-square/DOF ratio between 1 and 3 indicate adequate model fit. Finally, we presented the results of the path analysis model by showing standardized coefficients and goodness-of-fit statistics. All maximum-likelihood estimations for the model were computed using R (Version 1.3.959).

Table 3. Moral foundation dictionary.

\begin{tabular}{cccc}
\hline Category & Definition & Number of Words & Representative Words \\
\hline Harm Virtue & Words reflecting care & 40 & Care friendship \\
Harm Vice & Words reflecting hurt & 81 & Torture kill \\
Fairness Virtue & Words reflecting fairness & 38 & Decent equal \\
Fairness Vice & Words reflecting injustice & 34 & Fraud injustice \\
Ingroup Virtue & Words reflecting unity & 72 & Motherland unity \\
Ingroup Vice & Words reflecting rebellion & 53 & Treason heresy \\
Authority Virtue & Words reflecting authority & 83 & compliance \\
Authority Vice & Words reflecting revolt & 48 & demonstration \\
Purity Virtue & Words reflecting purity & 60 & loyalty chastity \\
Purity Vice & Words reflecting filthiness & 101 & Filth sin \\
Morality General & Words reflecting other general morality not mentioned & 73 & Praise value \\
\hline
\end{tabular}




\section{Results}

We described the statistical characteristics of our original data and presented bivariate correlations after standardization among the variables in our model (Table 4 and Figure 2). There were 7 individual variables and 5 social variables with large dimensional differences, which meant we need to make standardized processing of the original data collected. The correlation coefficient thermodynamic diagram showed that the independent variables harm vice and collectivism had strong correlation $(\rho>0.8)$. As for whether the two variables overlapped, we could further consider whether to modify the model according to the goodness of fit statistics of the path analysis model [33]. The descriptive statistic is shown in Table 4 and the correlation is shown in Figure 2.

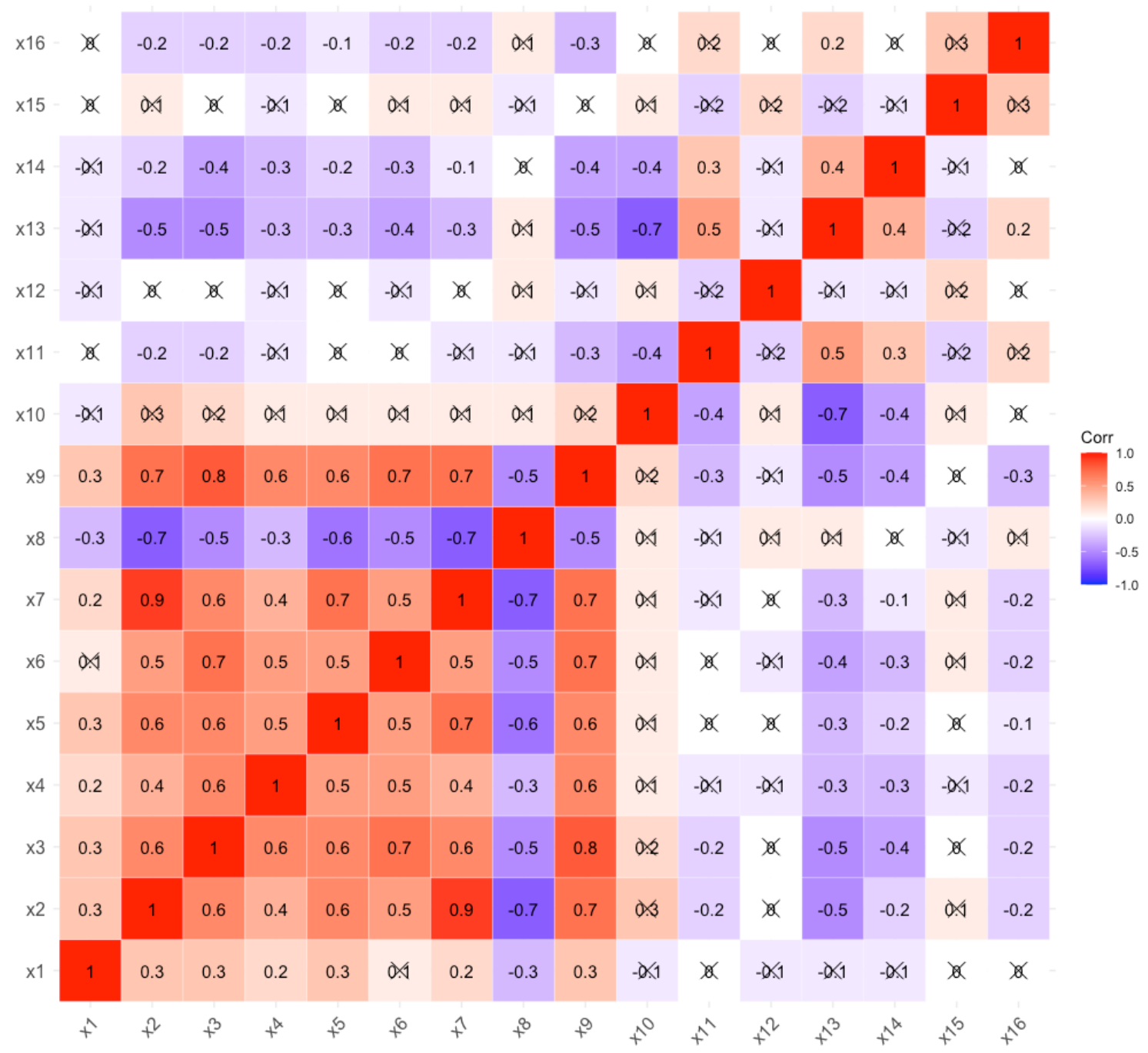

Figure 2. Thermodynamic diagram of correlation coefficient. Note: $\times 1$-Suicidal behavior, $\times 2$-Psychache, $\times 3$-Harm vice, $\times 4$-Fairness vice, $\times 5$-Ingroup vice, $\times 6$-Authority vice, $\times 7$-Purity vice, $\times 8$-Individualism, $\times 9$-Collectivism, $\times 10$-Proportion of the primary industry, $\times 11$-Public transport and car for every 10,000 people, $\times 12$-Urban population density, $\times 13$-Disposable income of residents, $\times 14$-Gross domestic product (GDP), $\times 15$-Urban registered unemployment rate, $\times 16$-Crude divorce rate; “ $\times$ "represents the correlation between variables is not significant $(p<0.05)$. 
Table 4. Descriptive statistics for variables (2013-2018).

\begin{tabular}{|c|c|c|c|c|c|}
\hline & Variable & & Data Sources & $\begin{array}{l}\text { Mean } \\
\left(10^{-4}\right)\end{array}$ & $\begin{array}{c}\text { SD } \\
\left(10^{-5}\right)\end{array}$ \\
\hline & $\begin{array}{l}\text { Dependent } \\
\text { variable }\end{array}$ & Suicidal behavior & $\begin{array}{l}\text { Chinese suicide } \\
\text { dictionary/ } \\
\text { Sina Weibo }\end{array}$ & 2.00 & 1.78 \\
\hline & $\begin{array}{l}\text { Mediating } \\
\text { variables }\end{array}$ & Psychache & $\begin{array}{l}\text { Chinese suicide } \\
\text { dictionary/ } \\
\text { Sina Weibo }\end{array}$ & 44.29 & 101.01 \\
\hline \multirow{7}{*}{$\begin{array}{l}\text { Cultural/Value } \\
\text { factors }\end{array}$} & \multirow{2}{*}{$\begin{array}{l}\text { Individualism and } \\
\text { collectivism }\end{array}$} & Individualism & $\begin{array}{l}\text { Cultural Value } \\
\text { Dictionary/ } \\
\text { Sina Weibo }\end{array}$ & 219.30 & 436.29 \\
\hline & & Collectivism & $\begin{array}{l}\text { Cultural Value } \\
\text { Dictionary/ } \\
\text { Sina Weibo }\end{array}$ & 76.74 & 60.46 \\
\hline & \multirow{5}{*}{ Social morality } & Harm vice & $\begin{array}{l}\text { Moral Foundation } \\
\text { Dictionary/ } \\
\text { Sina Weibo }\end{array}$ & 3.07 & 4.09 \\
\hline & & Fairness vice & $\begin{array}{l}\text { Moral Foundation } \\
\text { Dictionary/ } \\
\text { Sina Weibo }\end{array}$ & 0.61 & 0.83 \\
\hline & & Ingroup vice & $\begin{array}{l}\text { Moral Foundation } \\
\text { Dictionary/ } \\
\text { Sina Weibo }\end{array}$ & 1.18 & 1.96 \\
\hline & & Authority vice & $\begin{array}{l}\text { Moral Foundation } \\
\text { Dictionary/ } \\
\text { Sina Weibo }\end{array}$ & 1.02 & 1.41 \\
\hline & & Purity vice & $\begin{array}{l}\text { Moral Foundation } \\
\text { Dictionary/ } \\
\text { Sina Weibo }\end{array}$ & 4.23 & 19.46 \\
\hline \multirow{2}{*}{ Economic factors } & $\begin{array}{l}\text { Disposable income } \\
\text { of residents }\end{array}$ & $\begin{array}{l}\text { Disposable income } \\
\text { of residents } \\
\text { (yuan) }\end{array}$ & $\begin{array}{l}\text { National Bureau } \\
\text { of Statistics }\end{array}$ & $230,291,985$ & $1,000,441,740$ \\
\hline & $\begin{array}{l}\text { Gross domestic } \\
\text { product }\end{array}$ & $\begin{array}{c}\text { GDP } \\
\text { (million yuan) }\end{array}$ & $\begin{array}{l}\text { National Bureau } \\
\text { of Statistics }\end{array}$ & $246,386,565$ & $1,974,809,840$ \\
\hline \multirow{5}{*}{ Other factors } & \multirow{3}{*}{ Urbanization } & $\begin{array}{l}\text { Proportion of the primary } \\
\text { industry }\end{array}$ & $\begin{array}{l}\text { National Bureau } \\
\text { of Statistics }\end{array}$ & 957.67 & 4974.43 \\
\hline & & $\begin{array}{l}\text { Public transport and car } \\
\text { for every } 10,000 \text { people } \\
\text { (unit) }\end{array}$ & $\begin{array}{l}\text { National Bureau } \\
\text { of Statistics }\end{array}$ & $129,440.32$ & $317,058.75$ \\
\hline & & $\begin{array}{c}\text { Urban population density } \\
\text { (people per } \\
\text { square kilometer) }\end{array}$ & $\begin{array}{l}\text { National Bureau } \\
\text { of Statistics }\end{array}$ & $28,239,193.5$ & $112,142,778$ \\
\hline & Unemployment & $\begin{array}{l}\text { Urban registered } \\
\text { unemployment rate } \\
(\%)\end{array}$ & $\begin{array}{l}\text { National Bureau } \\
\text { of Statistics }\end{array}$ & $32,327.96$ & $64,073.42$ \\
\hline & Marriage & $\begin{array}{l}\text { Crude divorce rate } \\
\qquad(\%)\end{array}$ & $\begin{array}{l}\text { National Bureau } \\
\text { of Statistics }\end{array}$ & 2.934 & 0.96 \\
\hline
\end{tabular}

\section{The Path Analysis Model}

Maximum-likelihood estimations were used to estimate the path analysis model. Goodness of fit statistics indicated that the model was an adequate representation of the data. (Table 5). 
Table 5. Goodness of fit statistics of path analysis model.

\begin{tabular}{ccccc}
\hline \multicolumn{5}{c}{ Path Analysis Model Fit } \\
\hline$\chi^{2} /$ df $(<3)$ & RMSEA $(<\mathbf{0 . 0 8 )}$ & RMSEA 90\%CI & NFI $(>\mathbf{0 . 9 )}$ & CFI $(>\mathbf{0 . 9 )}$ \\
\hline 1.894 & 0.069 & {$[0.026,0.10]$} & 0.936 & 0.967
\end{tabular}

The path analysis model had acceptable model fit $\left(\chi^{2} / \mathrm{df}=1.894\right.$, RMSEA $=0.069$, $[0.026,0.10] 90 \% \mathrm{CI} N F I=0.981, \mathrm{CFI}=0.992)$. The path diagram of the model was illustrated in Figure 3. In addition, the standardized beta coefficients and $p$ value for estimates from the model were presented in Table 6 . With the mediator psychache, higher authority vice, higher individualism and higher disposable income of residents significantly predicted less suicidal behavior. Purity vice, collectivism and proportion of the primary industry had positive significant mediating effect on suicidal behavior via the mediator psychache. However, the coefficients of harm vice, fairness vice, ingroup vice, public transport and car for every 10,000 people, urban population density, GDP, urban registered unemployment rate and crude divorce rate did not have the mediating effect.

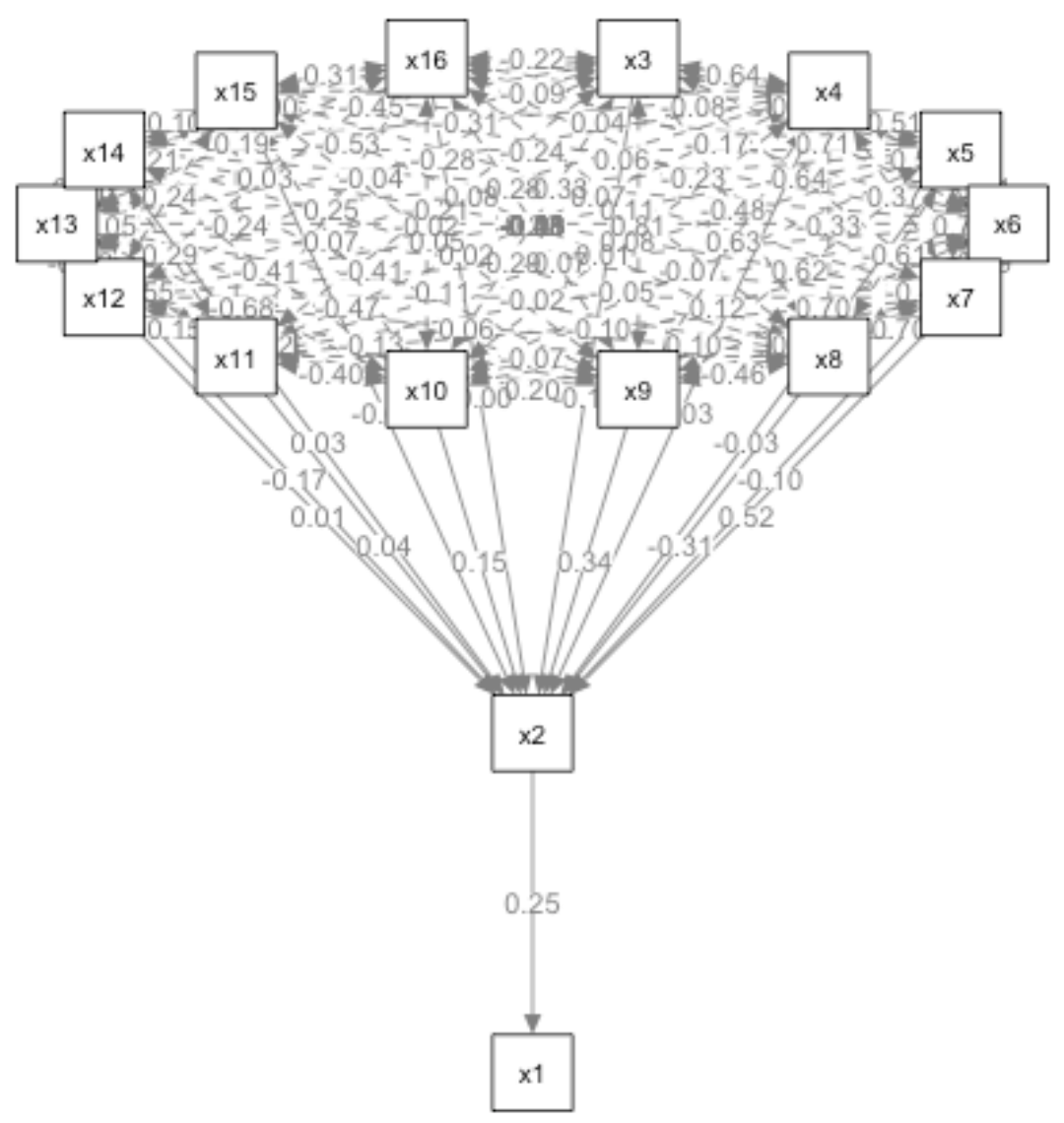

Figure 3. Path analysis model. Note: $\times 1$-Suicidal behavior, $\times 2$-Psychache, $\times 3$-Harm vice, $\times 4$-Fairness vice, $\times 5$-Ingroup vice, $\times 6$-Authority vice $\times 7$-Purity vice,$\times 8$-Individualism, $\times 9$-Collectivism, $\times 10$-Proportion of the primary industry, $\times 11$-Public transport and car for every 10,000 people, $\times 12$-Urban population density, $\times 13$-Disposable income of residents, $\times 14$-Gross domestic product $(\mathrm{GDP}), \times 15$-Urban registered unemployment rate, $\times 16$-Crude divorce rate. 
Table 6. Results of the path analysis model.

\begin{tabular}{|c|c|c|}
\hline Path & $\begin{array}{l}\text { Standardized } \\
\text { Estimate }\end{array}$ & $p(>|z|)$ \\
\hline $\begin{array}{c}\text { Psychache } \\
\text { psychache } \rightarrow \text { Suicidal behavior }\end{array}$ & 0.252 & $0.000^{* * *}$ \\
\hline \multicolumn{3}{|l|}{ Cultural/Value factors } \\
\hline $\begin{array}{l}\text { Individualism and collectivism } \\
\text { Individualism } \rightarrow \text { psychache } \rightarrow \text { Suicidal behavior } \\
\text { Collectivism } \rightarrow \text { psychache } \rightarrow \text { Suicidal behavior }\end{array}$ & $\begin{array}{c}-0.077 \\
0.086\end{array}$ & $\begin{array}{l}0.000^{* * *} \\
0.000^{* * *}\end{array}$ \\
\hline $\begin{array}{l}\text { Social morality } \\
\text { Harm vice } \rightarrow \text { psychache } \rightarrow \text { Suicidal behavior } \\
\text { Fairness vice } \rightarrow \text { psychache } \rightarrow \text { Suicidal behavior } \\
\text { Ingroup vice } \rightarrow \text { psychache } \rightarrow \text { Suicidal behavior } \\
\text { Authority vice } \rightarrow \text { psychache } \rightarrow \text { Suicidal behavior } \\
\text { Purity vice } \rightarrow \text { psychache } \rightarrow \text { Suicidal behavior }\end{array}$ & $\begin{array}{c}-0.028 \\
-0.007 \\
-0.007 \\
-0.026 \\
0.130\end{array}$ & $\begin{array}{c}0.055 \\
0.477 \\
0.520 \\
0.014^{* *} \\
0.000^{* * *}\end{array}$ \\
\hline \multicolumn{3}{|l|}{ Economic factors } \\
\hline $\begin{array}{l}\text { Disposable income of residents } \\
\text { Disposable income of residents } \rightarrow \text { psychache } \rightarrow \text { Suicidal behavior } \\
\text { Gross domestic product (GDP) } \\
\text { GDP } \rightarrow \text { psychache } \rightarrow \text { Suicidal }\end{array}$ & $\begin{array}{l}-0.044 \\
0.008\end{array}$ & $\begin{array}{l}0.000 * * * \\
0.362\end{array}$ \\
\hline \multicolumn{3}{|l|}{ Other factors } \\
\hline $\begin{array}{l}\text { Urbanization } \\
\text { Proportion of the primary industry } \rightarrow \text { psychache } \rightarrow \text { Suicidal behavior } \\
\text { Public transport and car for every } 10,000 \text { people } \rightarrow \text { psychache } \rightarrow \text { Suicidal behavior } \\
\text { Urban population density } \rightarrow \text { psychache } \rightarrow \text { Suicidal behavior }\end{array}$ & $\begin{array}{l}0.037 \\
0.011 \\
0.004\end{array}$ & $\begin{array}{l}0.000 * * * \\
0.214 \\
0.637\end{array}$ \\
\hline \multicolumn{3}{|l|}{ Unemployment } \\
\hline $\begin{aligned} & \text { Marriage } \\
\text { Crude divorce rate } \rightarrow & \text { psychache } \rightarrow \text { Suicidal behavior }\end{aligned}$ & -0.0002 & 0.975 \\
\hline
\end{tabular}

Note: ${ }^{* *} p<0.05,{ }^{* * *} p<0.01$.

Furthermore, in order to test whether the mediating effect of the model has cross group stability, in this study, we applied the model to three major economic development belts in China. According to the differences in natural conditions, economic resources, economic development level, transportation conditions, and economic benefits of various regions, China is divided into three major economic zones: the eastern coastal zone, the central zone, and the western zone [34]. If the results of multi-group analysis are not significant, it means economic zones have no effect on the complete mediating effect, and if there are significant differences, it means different economic zones have a moderator effect. The goodness of fit statistics of the multi-group complete mediating effect model were $\chi^{2} / \mathrm{df}=2.509$, RMSEA $=0.156, \mathrm{NFI}=0.823, \mathrm{CFI}=0.875$. This meant that different economic zones had no influence on the model designed in our study.

\section{Discussion}

In this study, the path analysis model was designed, and psychache was introduced as the mediation mediate variable. We found that authority vice, purity vice, individualism, collectivism, proportion of the primary industry, and disposable income of residents had mediating effects on suicidal behavior via the mediator psychache. Additionally, the path analysis model showed that harm vice, fairness vice, ingroup vice, public transport and car for every 10,000 people, urban population density, GDP, urban registered unemployment rate, and crude divorce rate had no mediating effect on suicidal behavior. To this end, our results in this study showed that psychache mediated the relationship between social 
factors (authority vice, purity vice, individualism, collectivism, proportion of the primary industry, and disposable income of residents) and suicidal behaviors.

\subsection{Cultural/Value Factors}

Both collectivism and individualism had indirect effects on suicidal behavior through the mediator psychache, but their effects were completely opposite one another. The results showed that the decrease in collectivism or the increase in individualism in social values could lead to a decrease in psychache, thus leading to the decrease of suicidal behavior. The reason for this result may be that too much emphasis placed on collectivism, especially in China, often means obligation, dedication, obedience, or even sacrifice of personal interests [35]. This collectivism is contrary to the individualistic thought brought about by China's rapid economic development and urbanization in recent decades [35]. Such conflicts and contradictions often bring negative emotions such as psychache to individuals. Thus, overemphasizing collectivism could lead to more psychache and ultimately to the increase of suicidal behavior, whereas more individualism could reduce psychache and thus reduce suicidal behavior.

Social morality. Authority vice, as a kind of behavior that breaks the hierarchical structure of the group, directly affected suicidal behavior [32]. Its standardized coefficient indicated an indirect negative correlation between authority vice and suicidal behavior. However, the psychology of authority has been studied in terms of fascism and blind obedience [36,37], and the individual who is forced to obey authority often experiences psychological pain [37]. In China, especially in rural areas, family ethics make family members have strong emotional expectations. Once the expectation fails, it can cause a strong emotional reaction to resist [5]. Suicide in China can be regarded as a means of rebelling against authority [38]. Too much emphasis on obedience to parents, the patriarchal clan system, village communities, and other authorities [39] may bring about painful psychological experiences for individuals, who may even commit suicide. Therefore, society pays attention to resisting authority, which encourages individuals to refuse to submit to authority, thus relieving psychache and reducing suicidal behavior. However, resistance to authority is the embodiment of individualism. Individualism resists authority and all attempts to control individuals, especially those imposed by the state or society. Individualism is a protective factor for suicidal behavior (this result has been proved in the previous part). When the population expresses more words resisting authority, it often means the awakening of individual consciousness.

Social morality. Purity vice, as a kind of behavior that suppresses selfishness, is often associated with humanity's carnal nature (e.g., lust, hunger, material greed) by cultivating a more spiritual mindset [40]. Its standardized coefficient suggested that higher purity vice would lead to more psychache and suicidal behavior. The psychology of purity and disgust has been related to stigma [41]. Stigma has a significant impact on self-esteem and a negative effect on mental health [42]. The frequent mention of purity vice words by an individual may be accompanied by an increase in stigma and negative mental health and a decrease in self-esteem, resulting in psychache and suicidal behavior.

\subsection{Economic Factors}

The indirect effect of disposable income of residents was significant. It revealed that residents' disposable income could alleviate the occurrence of suicide through the negative effect of psychache. A possible reason is that the lower the income, the lower the selfefficacy, and the greater the probability of negative emotions [43], with negative emotions such as psychache leading to suicidal behavior. Many studies have proved that low-income groups are more likely to commit suicide than high-income groups [44-46]. Based on the research above and the analysis of this paper, the mechanism behind the high suicide risk of low-income groups can be explained as follows: The negative emotion psychache caused by high income was reduced, which to some extent hindered the occurrence of suicidal behavior. The influence path of low income was just the opposite. The psychache 
of low-income groups will often stimulate the emergence of suicidal ideation. This suggests that measures should be taken to alleviate the psychache of low-income populations so as to reduce the possibility of suicide resulting from low income.

\subsection{Other Factors}

The coefficient of proportion of the primary industry to the suicidal behavior through psychache was 0.037 . A higher proportion of primary industries indicated a higher suicide rate. This result is supported by existing research. Suicide rate was positively associated with primary industry percentage with a significant tendency [47]. It should be noted that a higher proportion of the primary industry indicated that more people engaged in agricultural activities and lived in the countryside. Rural areas, the main concentration area of the primary industry, were indeed areas with high suicide rates in China from 1995-1999. The suicide rate in rural areas is three times higher than that in urban areas [48]. The decline of the primary industry and the development of the secondary and tertiary industries cause a large agricultural population to flow into the city, and they transform into a non-agricultural population. This process is often accompanied by the improvement of individual income levels [49], the awakening of individual consciousness [50], and less exposure to suicide tools such as pesticides (60\% of suicide in China was caused by pesticides) [48]. These factors are caused by the decrease in the proportion of the primary industry and its interaction with others to reduce psychache, thus reducing suicidal behavior.

\section{Implications}

The ultimate goal of the study was to develop a reliable and valid measure that can be used in suicide prevention services. The present study reached the goal of developing a reliable measure. Our study's results can play a role in implementing the formulation of relevant policies and social development.

\subsection{Encourage Individualism's Development in Collectivist Environments}

The study's results indicate that collectivism is a risk factor of suicide and that individualism is a protective factor. China is a typical collectivist country that has shown large effects, being both less individualistic and more collectivistic [51]. Especially to the east of the Hu Huanyong line and to the south of the Qinling Huaihe line, provinces such as Jiangsu, Anhui, Shanghai, Sichuan, and Yunnan are the most collectivistic regions in China [52]. Relevant departments in these areas should seize the opportunity of the growing awakening of individual consciousness and encourage individuals to embrace their independence and initiative in the field of production and life [53]. Specifically, in the areas where collectivism prevails, the government should vigorously improve people's mental health quality, popularize mental health knowledge, establish community psychological counseling, and improve the mental health care system. This can not only promote collectivism's development [53] but can also reduce suicidal behavior.

\subsection{Pay Attention to Primary Industry Practitioners' Mental Health Problems and Advocate the Reform of the Industrial}

The proportion of the primary industry is a risk factor of suicide. This conclusion inspires us to formulate corresponding policies from two perspectives. On the one hand, the government should pay more attention to the mental health of primary industry practitioners. According to our analysis, relevant departments are supposed to pay more attention to the psychological counseling of populations engaged in the primary industry. More specifically, the government can issue a series of policies to encourage the counselors to pay attention to the mental health of the primary industry practitioners, especially the rural farmers, and tilt the psychological resources to the rural areas. In addition, the government can open more consultation hotlines for suicide prevention or involve more knowledge about suicide prevention in the daily cultural propaganda of rural communities. 
On the other hand, the government needs to encourage industrial reform so as to reduce the number of practitioners in the primary industry. The local government should vigorously accelerate the upgrading of the primary industry's industrial structure through scientific and technological innovation and industrial agglomeration [54].The adjustment of the industrial structure of the primary industry is conducive to the adjustment of the employment structure of the primary industry $[55,56]$. After structural reform, the primary industry can not only reduce the population engaged in the primary industry properly but can also improve production efficiency, reduce suicide, and promote social development.

\subsection{Pay Attention to Low-Income People's Mental Health Problems and Improve the Disposable Income of Residents}

This study showed that disposable income is a protective factor of suicide. Higher disposable income can alleviate psychache and reduce suicidal behavior. Therefore, relevant departments should pay more attention to the mental health of low-income people and incline more mental resources to avoid the suicide of low-income individuals. For example, we suggest that the government popularize mental health knowledge to low-income groups free of charge and open a free psychological counseling hotline. However, to fundamentally solve suicide caused by low income, it is necessary for local governments to create employment opportunities, promote economic growth [57], reform the tax system [58], improve the financial market and promote the diversification of residents' property [59], and use other methods to improve residents' disposable income so as to avoid the negative impact of low disposable income.

\subsection{Advocate the Social Morality of Pure and Non-Superstitious Authority}

Higher purity vice will promote suicide, whereas less authority vice will reduce the occurrence of suicide. The government can formulate policies from the perspective of education, civilizing people's customers, and strengthening the legal system to promote the establishment of a pure and non-superior society [60].

\section{Limitations}

Although there are important discoveries revealed by this research, there are also limitations. First, the data selected are biased. Users of Sina Weibo tend to be younger, so this study ignores the suicidal behavior of elderly and non-microblog users. Thus, there may be some bias in the results. Second, it is also worth noting that some independent variables that are considered to be related to suicidal behaviors were not significant in the analysis. Perhaps they are not significant because our research was mainly based on Shneidman's theory [12], which regards psychache (negative hurt, mental pain, soreness) as the cause of all suicidal behaviors. Thus, psychache was the only mediator in our model. It simplified the psychological mechanism. Therefore, it is not comprehensive to attribute all social factors influencing suicidal behavior only through psychache. In reality, the psychological mechanism of suicidal behavior may be more complex, which requires further study.

\section{Conclusions}

We used the path analysis model to analyze the mediating mechanism of social factors on suicidal behavior. We applied our model to three major economic development belts in China to test whether the mediating effect had differences. Our study found that harm vice, fairness vice, ingroup vice, public transport and car for every 10,000 people, urban population density, GDP, urban registered unemployment rate, and crude divorce rate had no significant mediating effect on suicidal behavior. Authority vice, purity vice, individualism, collectivism, proportion of the primary industry, and disposable income of residents had significant mediating effects on suicidal behavior via the mediator psychache, and the mediating effect of our model had no differences in different areas of China. These results bring new inspiration to our prevention of suicidal behavior at the social 
level. Future research needs to test whether more diverse populations meet the results of this study.

Author Contributions: Conceptualization: Y.H., H.L., A.L. and T.Z.; methodology, Y.H., H.L., and T.Z.; investigation, H.L. and Y.H.; resources, T.Z.; writing—original draft preparation, Y.H. writingreview and editing, Y.X., A.L. and T.Z.; funding acquisition, T.Z. All authors have read and agreed to the published version of the manuscript.

Funding: This research was funded by China Social Science Foundation (grant number 17AZD041), and National Natural Science Foundation of China (grant number 92046006).

Institutional Review Board Statement: The study was approved by the Research Ethics Committee of the Institute of Psychology, Chinese Academy of Sciences, ethic code is H15009.

Informed Consent Statement: Informed consent was obtained from all subjects involved in the study.

Data Availability Statement: Restrictions apply to the availability of these data. Data was obtained from Weibo and are available at (https://weibo.com) with the permission of Weibo.

Conflicts of Interest: The authors declare no conflict of interest.

\section{References}

1. World Health Organization. ZH 09-011209 Article; World Health Organization: Geneva, Switzerland, 2009.

2. Wang, Y. National Disease Surveillance System Death Cause Monitoring Data Set; Military Medical Science Press: Beijing, China, 2012.

3. Hawton, K.; Heeringen, K.V. Chapter 1. Suicide in the Western World; John Wiley \& Sons, Ltd.: Hoboken, NJ, USA, 2008.

4. Schlebusch, L. Depression and Suicidal Behaviour. S. Afr. Fam. Pract. 2015, 47, 61-63. [CrossRef]

5. Wang, Y.-T. Resistance and Liberation: A Comparative Study on Farmers' Suicides in Jiangxi and Hubei. J. Huazhong Univ. Sci. Technol. (Soc. Sci. Ed.) 2012, 26, 117-124.

6. Ku, S. Research on suicide trajectory pattern. Soc. Sci. Res. 2002, 6, 115-118.

7. Hu, J.; Dong, Y.; Chen, X.; Liu, Y.; Ma, D.; Liu, X.; Zheng, R.; Mao, X.; Chen, T.; He, W. Prevalence of suicide attempts among Chinese adolescents: A meta-analysis of cross-sectional studies. Compr. Psychiatry 2015, 61, 78-89. [CrossRef]

8. While, D.; Bickley, H.; Roscoe, A.; Windfuhr, K.; Rahman, S.; Shaw, J.; Appleby, L.; Kapur, N. Implementation of mental health service recommendations in England and Wales and suicide rates, 1997-2006: A cross-sectional and before-and-after observational study. Lancet 2012, 379, 1005-1012. [CrossRef]

9. Sharaf, A.Y.; Ossman, L.H.; Lachine, O.A. A cross-sectional study of the relationships between illness insight, internalized stigma, and suicide risk in individuals with schizophrenia. Int. J. Nurs. Stud. 2012, 49, 1512-1520. [CrossRef] [PubMed]

10. Zhang, J.; Lu, J. Association between community environment and suicidal behavior. Chin. J. Behav. Med. Brain Sci. 2013, 22, 1024-1027.

11. Mann, J.J.; Waternaux, C.; Haas, G.L.; Malone, K.M. Toward a clinical model of suicidal behavior in psychiatric patients. Am. J. Psychiatry 1999, 156, 181-189.

12. Shneidman, E.S. The Suicidal Mind; Oxford University Press: New York, NY, USA, 1996.

13. Gu, X.; Zhang, $Z$. The significance, problems and reflection of emotional expression of expression pack in social media. China Youth Res. 2018, 12, 26-31.

14. Liu, X.; Sun, B.; Wang, X.; Jiao, D.; Liu, X.; Zhu, T. Active identification and timely intervention of suicide manifesto based on microblog big data. In Proceedings of the 20th National Conference on psychology abstracts of psychology and national mental health, Chongqing, China, 4-5 November 2017.

15. Tian, W.; Zhu, T. Suicide risk prediction of microblog users based on deep learning. J. Univ. Chin. Acad. Sci. 2018, 35, 131-136.

16. Beck, A.T.; Schuyler, D.; Herman, I. Development of Suicidal Intent Scales; Charles Press Publishers: Philadelphia, PA, USA, 1974.

17. Beck, A.T.; Kovacs, M.; Weissman, A. Assessment of suicidal intention: The Scale for Suicide Ideation. J. Consult. Clin. Psychol. 1979, 47, 343-352. [CrossRef]

18. Delisle, M.M.; Holden, R.R. Differentiating between Depression, Hopelessness, and Psychache in University Undergraduates. Meas. Eval. Couns. Dev. 2009, 42, 46-63. [CrossRef]

19. Troister, T.; Davis, M.P.; Lowndes, A.; Holden, R.R. A five-month longitudinal study of psychache and suicide ideation: Replication in general and high-risk university students. Suicide Life Threat. Behav. 2013, 43, 611-620. [CrossRef]

20. Lester, D. Patterns of Suicide and Homicide in the World; Nova Science Publishers: Hauppauge, NY, USA, 1996; 167p.

21. Jollant, F; Malafosse, A.; Docto, R.; Macdonald, C. A pocket of very high suicide rates in a non-violent, egalitarian and cooperative population of South-East Asia. Psychol. Med. 2014, 44, 2323-2329. [CrossRef] [PubMed]

22. Baudelot, C.; Establet, R. Suicide. L'envers de Notre Monde [EB/OL]. Available online: https://journals.openedition.org/sdt/20 850 (accessed on 9 October 2020).

23. Zhang, W.; Li, M. Research on the definition of urbanization. Urban Dev. Res. 2000, 5, 32-33. 
24. Otsu, A.; Araki, S.; Sakai, R.; Yokoyama, K.; Voorhees, A.S. Effects of urbanization, economic development, and migration of workers on suicide mortality in Japan. Soc. Sci. Med. 2004, 58, 1137-1146. [CrossRef]

25. Quinney, R. Suicide, Homicide, and Economic Development. Soc. Forces 1965, 43, 401-406. [CrossRef]

26. Reeves, A.; Mckee, M.; Stuckler, D. Economic suicides in the Great Recession in Europe and North America. Br. J. Psychiatry J. Ment. Sci. 2014, 205, 246. [CrossRef]

27. Stack, S.; Wasserman, I. The effect of marriage, family, and religious ties on African American suicide ideology. J. Marriage Fam. 1995, 57, 215-222. [CrossRef]

28. Wang, J.; Yi, D.; Guo, L. Study on the construction and evaluation of China's new urbanization index system. Mod. Manag. Sci. 2015, 6, 64-66.

29. Lv, M.; Li, A.; Liu, T.; Zhu, T. Creating a Chinese suicide dictionary for identifying suicide risk on social media. PeerJ 2015, 3, e1455. [CrossRef]

30. Ren, X.; Xiang, Y.; Zhou, Y.; Zhu, T. Psychological map of individualism/collectivism of Chinese people based on microblog big data. J. Inn. Mong. Norm. Univ. Philos. Soc. Sci. 2017, 46, 59-64.

31. Wu, S.; Yang, C.; Zhang, Y. Introduction and preliminary analysis of the Chinese version of moral foundation dictionary. Psychol. Meas. 2019. [CrossRef]

32. Graham, J.; Haidt, J.; Nosek, B.A. Liberals and conservatives rely on different sets of moral foundations. J. Personal. Soc. Psychol. 2009, 96, 1029. [CrossRef]

33. Wang, J.; Wang, X.; Jiang, B. Structural Equation Modeling: Method and Application; Higher Education Press: Beijing, China, 2011.

34. The Seventh Five Year Plan for National Economic and Social Development of the People's Republic of China (1986-1990); People's Publishing House: Beijing, China, 1983.

35. Zeng, R.; Greenfield, P.M. Cultural evolution over the last 40 years in China: Using the Google Ngram Viewer to study implications of social and political change for cultural values. Int. J. Psychol. 2015, 50, 47-55. [CrossRef] [PubMed]

36. Altemeyer, B. The Authoritarian Specter; Harvard University Press: Cambridge, MA, USA, 1996; 384p.

37. Milgram, S. Obedience to Authority; Harper \& Row: New York, NY, USA, 1974.

38. Ji, J.; Kleinman, A.; Becker, A.E. Suicide in contemporary China: A review of China's distinctive suicide demographics in their sociocultural context. Harv. Rev. Psychiatry 2001, 9, 1-12. [CrossRef] [PubMed]

39. Dang, G.Y. Structural change of social authority and rural stability in rural Chin. China Rural Obs. 1997, 5, 3-11.

40. Shweder, R.A.; Much, N.C.; Mahapatra, M.; Park, L. The “Big Three" of Morality (Autonomy, Community, Divinity) and the "Big Three" Explanations of Suffering. In Morality and Health; Brandt, A.M., Rozin, P., Eds.; Taylor \& Frances/Routledge: Abingdon, UK, 1997; pp. 119-169.

41. Crocker, J.; Major, B. Social stigma and self-esteem: The self-protective properties of stigma. Psychol. Rev. 1989, 96, 608-630. [CrossRef]

42. Gao, J.; Qian, M. Two sides of shame: Function and pathology. Chin. J. Ment. Health 2009, 23, 451-456.

43. Wang, S. Analysis of the influence of family income on the evaluation of negative emotions of physical examination objects. Fam. Med. 2019, 4, 250.

44. Ferrada-Noli, M. Social psychological variables in populations contrasted by income and suicide rate: Durkheim revisited. Psychol. Rep. 1997, 81, 307-316. [CrossRef]

45. Sher, L. Per capita income is related to suicide rates in men but not in women. J. Mens Health Gend. 2006, 3, 39-42. [CrossRef]

46. Wang, X.; Jia, C.; Zhang, J.; Wang, D. The relationship between family cohesion and adaptability and rural suicide. China Public Health 2012, 2, 50-52.

47. Nishimura, M.; Terao, T.; Soeda, S.; Nakamura, J.; Iwata, N.; Sakamoto, K. Suicide and occupation: Further supportive evidence for their relevance. Prog. Neuro-Psychopharmacol. Biol. Psychiatry 2004, 28, 83-87. [CrossRef] [PubMed]

48. Phillips, M.R.; Li, X.; Zhang, Y. Suicide rates in China, 1995-1999. Lancet 2002, 359, 835-840. [CrossRef]

49. Li, S. Rural labor mobility and income growth and distribution in China. China Soc. Sci. 1999, 2, $16-33$.

50. Gao, C.; Yang, B. Interest based social interaction: The communication logic in the social network of fellow townspeople-A study of virtual ethnography based on QQ group of "SZ people in Beijing". Peking Univ. News Commun. Rev. 2013, 1, 94-111.

51. Oyserman, D.; Coon, H.M.; Kemmelmeier, M. Rethinking individualism and collectivism: Evaluation of theoretical assumptions and meta-analyses. Psychol. Bull. 2002, 128, 3. [CrossRef]

52. Ren, X.; Xiang, Y.; Ma, X. Three line theory of regional differences of Chinese collectivism. Res. Community Psychol. 2018, 1, 22-36.

53. Zheng, C. Interpretation and development of collectivism from the perspective of individual freedom and overall development. Res. Mao Zedong Deng Xiaoping Theory 2015, 8, 65-68.

54. Zhao, D.; Ren, X.; Tang, Z.; Li, B. Research on China's service industry agglomeration based on spatial statistics. J. Changchun Univ. Technol. (Soc. Sci. Ed.) 2013, 7, 68-71.

55. Guo, D.; Gu, H.; Yin, H. Analysis of rural labor employment in China based on rural industrial structure adjustment. China Soft Sci. 2010, 1, 18-24.

56. He, D.; Yao, Z. The effect of China's industrial structure adjustment, optimization and upgrading objectives and policy measures. Chin. Ind. Econ. 2008, 5, 46-56.

57. Chen, H. Analysis on the current situation of disposable income of urban residents and Countermeasures: A case study of Hubei Province since 1990. East China Econ. Manag. 2007, 21, 74-78. 
58. Yang, W. Play the role of tax regulation to increase the proportion of residents' Income: A case study of Guangdong Province. Tax Res. 2009, 2, 12-16.

59. Xu, S.; Tong, Y. Suggestions on improving the disposable income of Chinese Residents-Based on the comparison of national income distribution patterns of China, Japan and the United States. J. Zhengzhou Inst. Aeronaut. Ind. Manag. 2012, 30, 7-11.

60. Zhang, Y. How to build a good social atmosphere. Gov. Leg. Syst. 2014, 28, 51. 